\title{
Anatomia cirúrgica do fígado 1
}

\author{
Tarcisio Triviño ${ }^{2}$ \\ Simone de Campos Vieira Abib ${ }^{3}$
}

\begin{abstract}
Triviño T, Abib SCV. Anatomia cirúrgica do fígado. Acta Cir Bras [serial online] 2003 Set-Out;18(5). Disponível em URL: http://www.scielo.br/acb.

RESUMO - Objetivo: Estudar a anatomia funcional do fígado, sua segmentação, tendo como referência às estruturas vasculares, venosas, no interior do parênquima. Métodos: Dissecção em fígados de cadáveres recentes, identificando, na intimidade dos órgãos, os pedículos portais e as veias hepáticas, definindo, assim, os segmentos hepáticos ou unidades funcionais do fígado. Resultados: Caracterização anatômica dos segmentos hepáticos, em número de 8 , suas estruturas vasculares aferentes e eferentes, orientando ressecções anatômicas, regradas, preservando a vitalidade e função dos segmentos remanescentes. Conclusão: O conhecimento da anatomia funcional do fígado, baseada na sua segmentação, constitui a base para a moderna cirurgia hepática.
\end{abstract}

DESCRITORES - Anatomia funcional. Segmentação hepática. Fígado.

\section{Introdução}

Embora a cirurgia hepática tenha sua origem em tempos remotos, seu desenvolvimento e consolidação ocorreram apenas nos últimos 50 anos, evoluindo dos desbridamentos e ressecções de necessidade às ressecções anatômicas e, finalmente, à ressecção total do fígado seguida do transplante ortotópico.

Em 1854, Francis Glisson publica "Anatomia Hepatis“, marco no estudo da anatomia e fisiologia do fígado, onde o autor faz referência à circulação hepática e, principalmente, à existência de uma rede vascular comunicando os sistemas da veia porta e das veias hepáticas.

Embora alguns procedimentos cirúrgicos sobre o fígado tenham sido executados no final do século XIX e primeira metade do século XX, a moderna cirurgia hepática parece iniciar-se por volta de 1950.

Para tanto contribuíram, sobremaneira, os estudos anatômicos do fígado, de caráter funcional, desenvolvidos por McIndoe e Counseller ${ }^{1}$, Hjortsjo ${ }^{2}$, Goldsmith e Woodburne $^{3}$ e, principalmente, os trabalhos de
Couinaud $^{4}$, que estabeleceram, definitivamente, a segmentação hepática.

Enquanto o transplante hepático busca a solução para as doenças difusas do fígado, as ressecções clássicas - hepatectomia direita, esquerda e ampliadas - e as ressecções segmentares, destinam-se ao tratamento das lesões focais do fígado.

A realização destas ressecções implica no conhecimento detalhado da anatomia do fígado, uma vez que tais procedimentos devem respeitar a vascularização hepática e a individualidade funcional de cada segmento hepático.

A busca destes conhecimentos levou os autores ao estudo da anatomia do fígado, particularmente dos elementos vasculares, e, conseqüentemente, a segmentação hepática, em peças de cadáveres recentes, inicialmente no extinto Serviço de Verificação de Óbitos do Departamento de Anatomia Patológica da UNIFESPEPM (1993 a 1995) e, posteriormente, no Instituto de Medicina Legal da Secretaria de Segurança Pública do Estado de São Paulo (1999).

1. Trabalho realizado na Disciplina de Gastroenterologia Cirúrgica do Depto. de Cirurgia da Universidade Federal de São Paulo Escola Paulista de Medicina (UNIFESP - EPM), no Depto. de Anatomia Patológica da UNIFESP e no Instituto de Medicina Legal da Secretaria de Segurança Pública do Estado de São Paulo.

2. Prof. Adjunto, Doutor, Chefe da Disciplina de Gastroenterologia Cirurgica do Depto. de Cirurgia da UNIFESP - EPM.

3. Pós-graduanda da Disciplina de Cirurgia Pediátrica do Depto. de Cirurgia da UNIFESP - EPM. 
Tais conhecimentos, aqui apresentados, permitem preservar as estruturas vasculares, reduzindo o sangramento intra-operatório, principal obstáculo às ressecções hepáticas, assim como manter a vitalidade do parênquima remanescente.

\section{Anatomia cirúrgica do fígado}

A anatomia do fígado assume características distintas, se considerados aspectos morfológicos ou funcionais.

Morfologicamente, ou seja, da maneira como o órgão é visto a laparotomia, o fígado apresenta 4 lobos, sendo dois maiores e dois menores.

Os dois lobos maiores, direito e esquerdo, são separados pela fissura umbilical na face inferior e pelo ligamento falciforme na face ântero-superior. Entre eles há uma nítida diferença de volume com acentuado predomínio do direito sobre o esquerdo.

$\mathrm{Na}$ face inferior do lobo direito, a fissura transversa ou hilar, região onde penetram no parênquima hepático os ramos da veia porta, da artéria hepática e os ductos biliares, delimita dois pequenos lobos, um anterior, conhecido como lobo quadrado e outro posterior, conhecido como lobo caudado ou de Spiegel.

Conclui-se que a anatomia morfológica do fígado divide o órgão em lobos, delimitados por sulcos ou fissuras, elementos anatômicos facilmente identificáveis na superfície da glândula (Figuras 1 e 2).
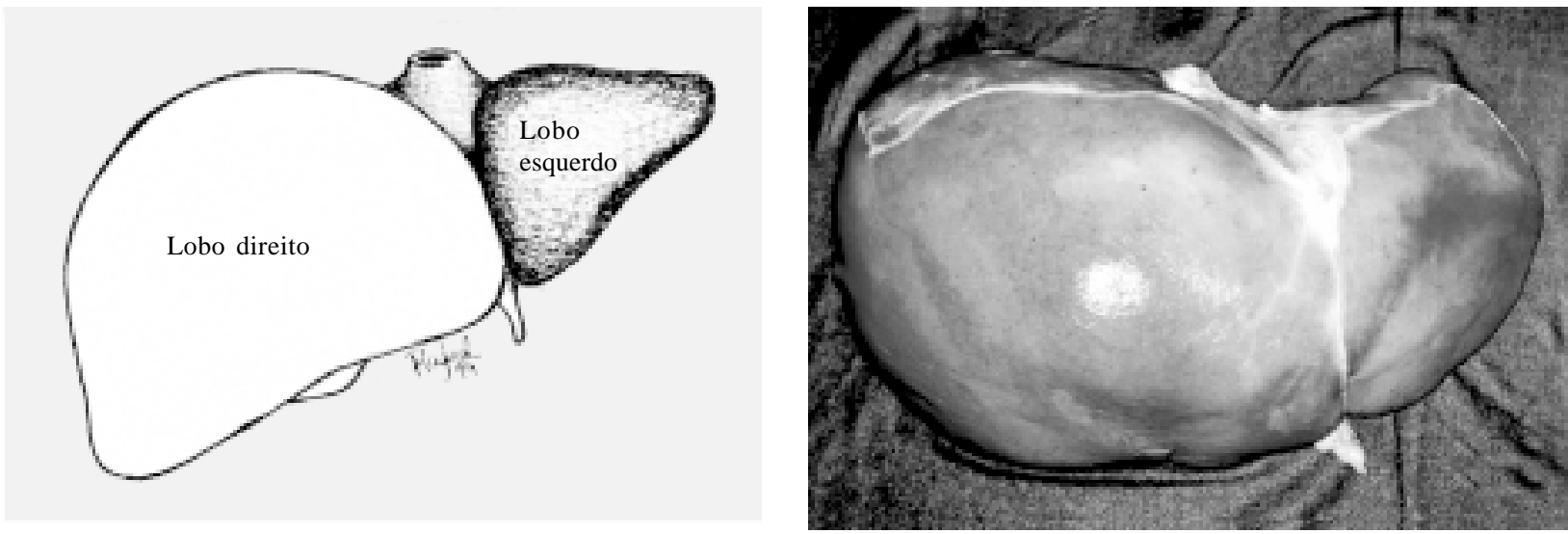

FIGURA 1 - Anatomia morfológica do fígado. Face ântero-superior.
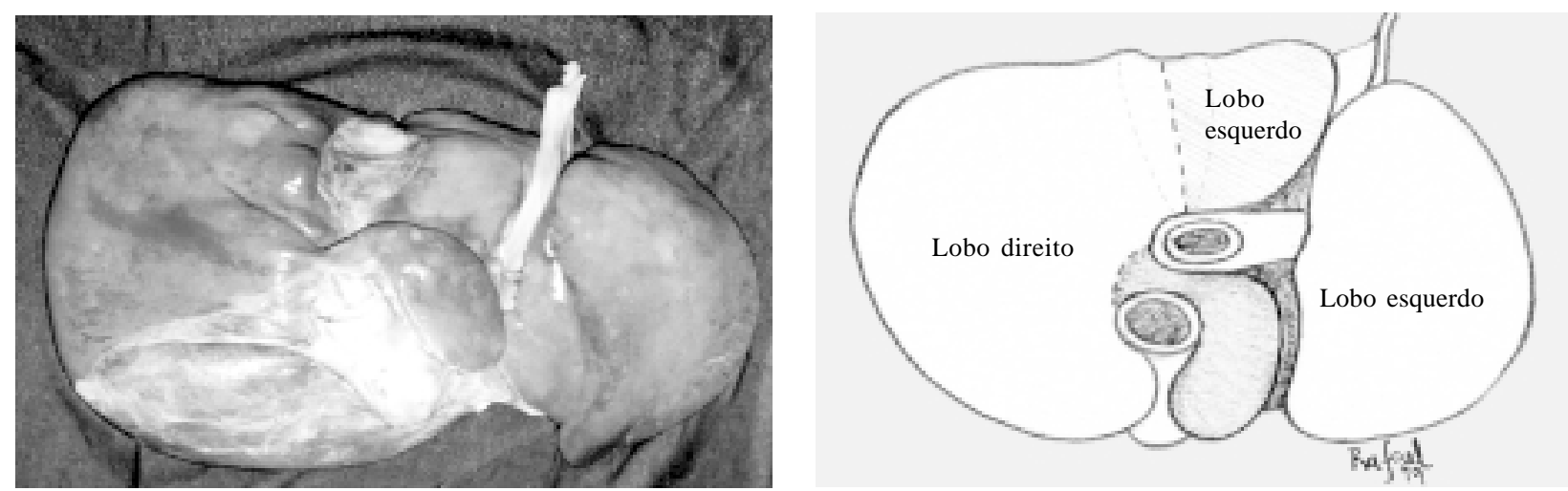

FIGURA 2 - Anatomia morfológica do fígado. Face inferior.

A anatomia funcional do fígado teve início com os trabalhos de McIndoe e Counseller ${ }^{1}$, Hjortsjö ${ }^{2}$, Couinaud $^{4}$ e Goldsmith e Woodburne ${ }^{3}$. As divisões e nomenclatura propostas por Couinaud ${ }^{4}$ são aquelas adotadas neste trabalho.

Funcionalmente, o fígado é dividido em dois hemifígados, conhecidos como fígados direito e esquerdo, os quais, por sua vez, são divididos em setores e segmentos, tendo como elementos de definição os pedículos portais e as veias hepáticas.

Diferentes dos lobos direito e esquerdo da anatomia morfológica, inclusive com volumes menos díspares, são absolutamente individualizados no que diz respeito aos fluxos portal e arterial, drenagem biliar e drenagem venosa, sendo, portanto, funcionalmente distintos. 
Os fígados direito e esquerdo são separados pela cisura portal principal, também conhecida como linha de Cantlie, que corresponde a uma linha que, originando-se no ponto médio do leito vesicular, anteriormente,

dirige-se posteriormente, ao longo da face ânterosuperior do fígado, à face lateral esquerda da veia cava na sua porção supra-hepática (Figura 3).

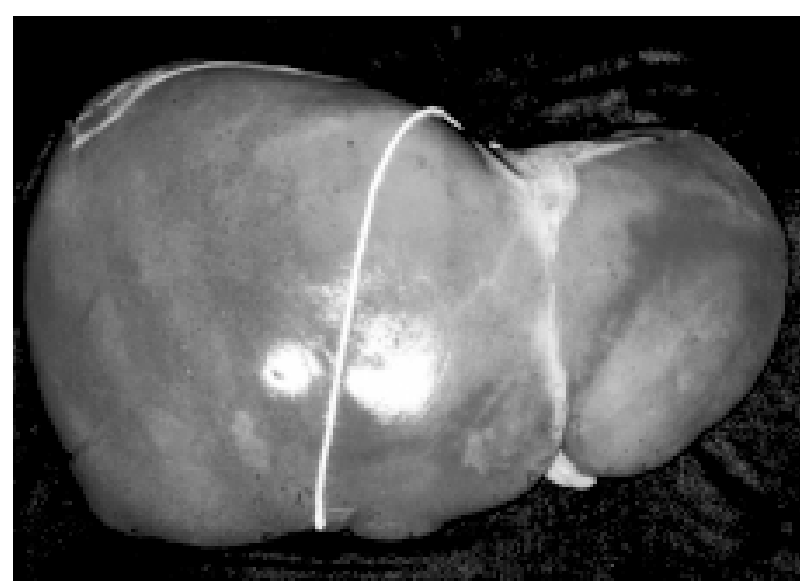

FIGURA 3 - Anatomia funcional do fígado. Face ântero-superior

Na intimidade do parênquima, esta linha corresponde ao curso da veia hepática média (Figuras 6 e 8).

$\mathrm{Na}$ face inferior, a linha que divide os dois fígados, originando-se no ponto médio do leito vesicular, ante- riormente, dirige-se posteriormente passando pela borda direita da fissura hilar, atingindo o lobo caudado ao nível do processo caudado (Figura 4).
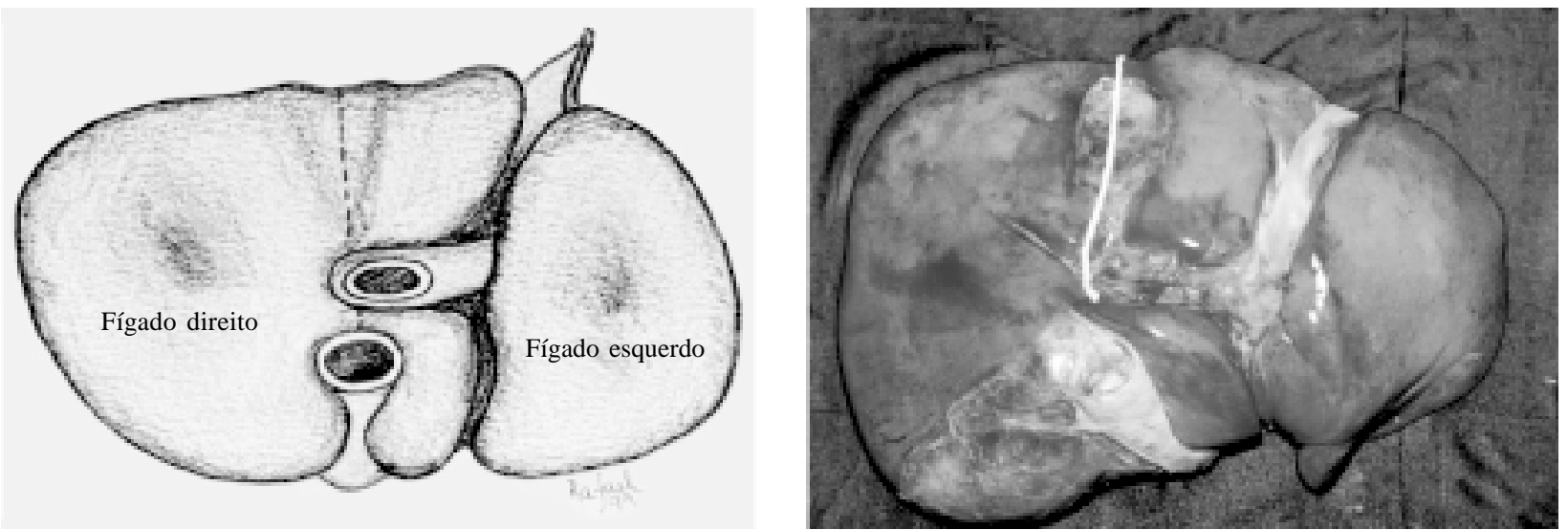

FIGURA 4 - Anatomia funcional do fígado. Face inferior.

Os fígados direito e esquerdo, por sua vez, são divididos em duas porções cada um, por duas outras cisuras, direita e esquerda, respectivamente.

A cisura portal direita é representada por uma linha que se origina, anteriormente, a meia distância entre o lado direito da fossa vesicular e o ângulo direito da borda hepática, dirigindo-se, ântero-posteriormente, à face lateral direita da veia cava suprahepática, onde esta recebe a veia hepática direita ${ }^{4}$ (Figura 5). 

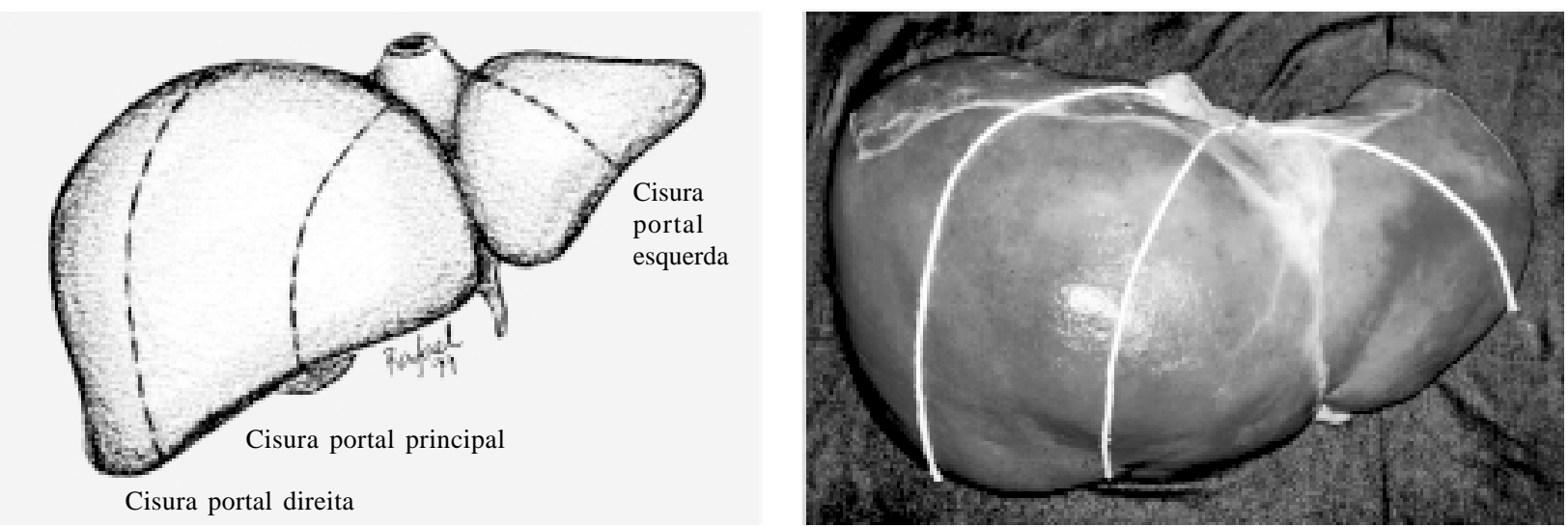

FIGURA 5 - Cisuras portais do fígado.

$\mathrm{Na}$ intimidade do parênquima, esta linha corresponde ao curso da veia hepática direita (Figuras 6 e 7) e é responsável pela divisão do fígado direito em

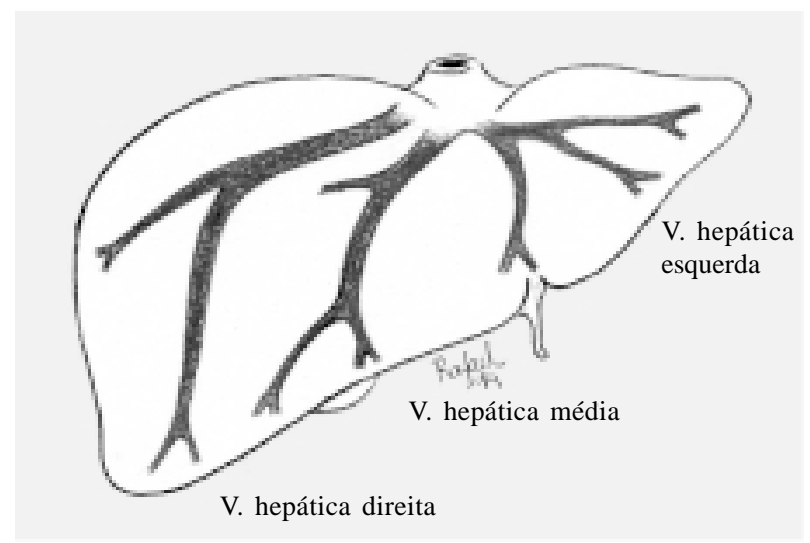

FIGURA 6 - Veias hepáticas.

Na face inferior, do ponto de origem anteriormente referido, esta linha se dirige ao ângulo externo da fissura hilar (Figura 12).

A cisura portal esquerda corresponde a uma linha de trajeto arciforme que originando-se a meia distância entre a extremidade do fígado esquerdo e a fissura umbilical e o ligamento teres, anteriormente, dirige-se posteriormente em direção a face lateral esquerda da veia cava supra-hepática, no ponto em esta recebe a veia hepática esquerda (Figura 5).

$\mathrm{Na}$ intimidade do parênquima esta linha corresponde ao curso da veia hepática esquerda (Figuras dois setores, póstero-lateral direito ou posterior simplesmente, e ântero-lateral direito ou anterior ${ }^{5}$ (Figura 11).

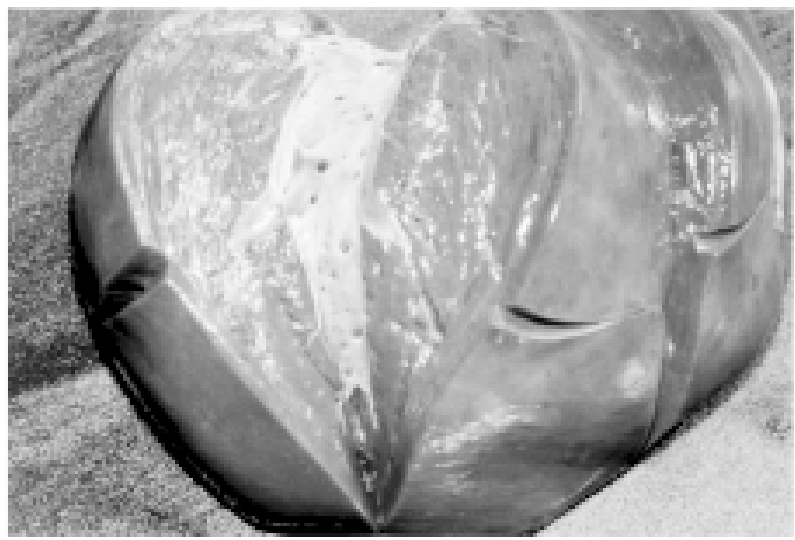

FIGURA 7 - Veia hepática direita.

6 e 9) e é responsável pela divisão do fígado esquerdo em dois setores, um posterior ou lateral e outro anterior ou medial (Figura 11).

$\mathrm{Na}$ face ventral do fígado, esta cisura, do ponto de origem na borda hepática, dirige-se ao ângulo esquerdo da fissura hilar (Figura 12).

A fissura umbilical, que não é uma cisura portal, pois não contém veia hepática, e sim pedículo portal, divide, por sua vez, o setor anterior ou medial do fígado esquerdo, em duas porções, uma ântero-medial e outra ântero-lateral ${ }^{5}$. 


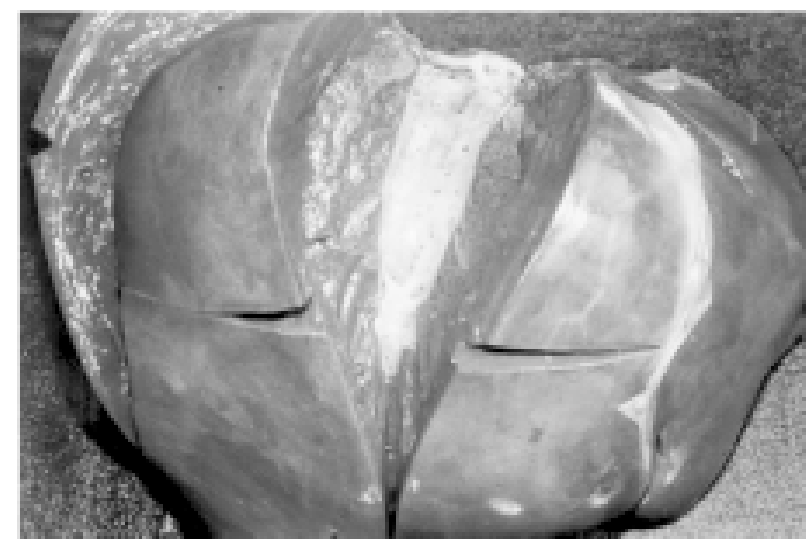

FIGURA 8 - Veia hepática média.

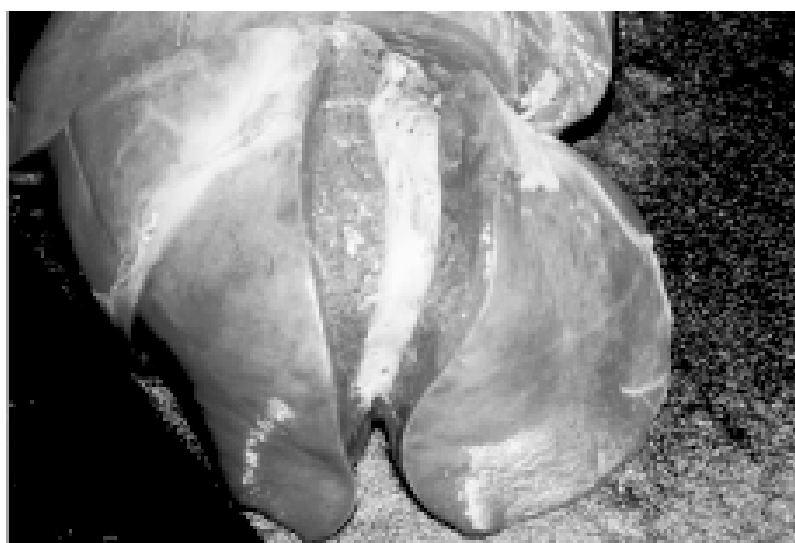

FIGURA 9 - Veia hepática esquerda.

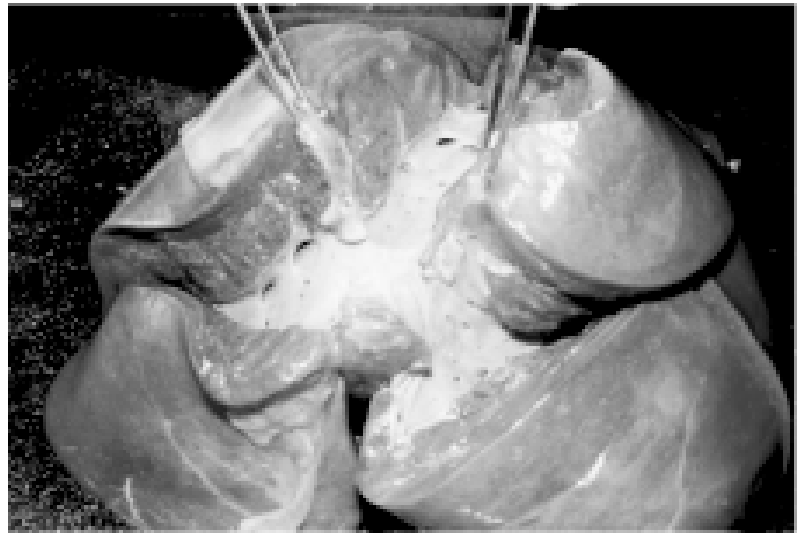

FIGURA 10 - Confluência das veias hepáticas.
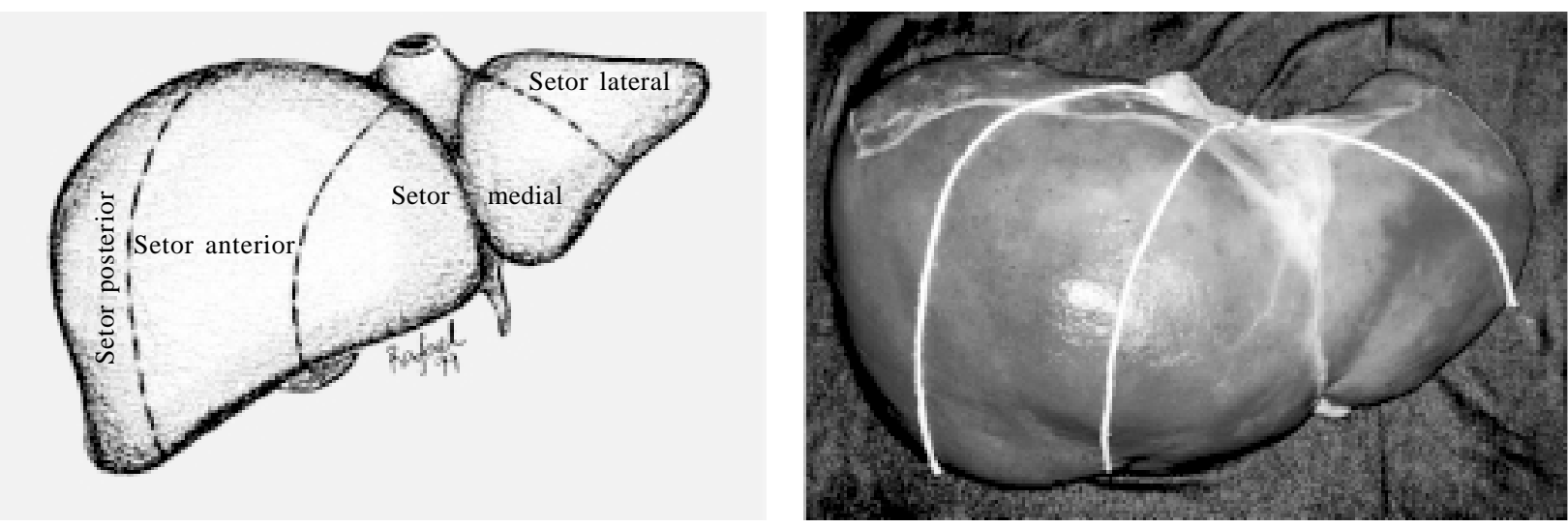

FIGURA 11 - Setores portais. Face ântero-superior. 

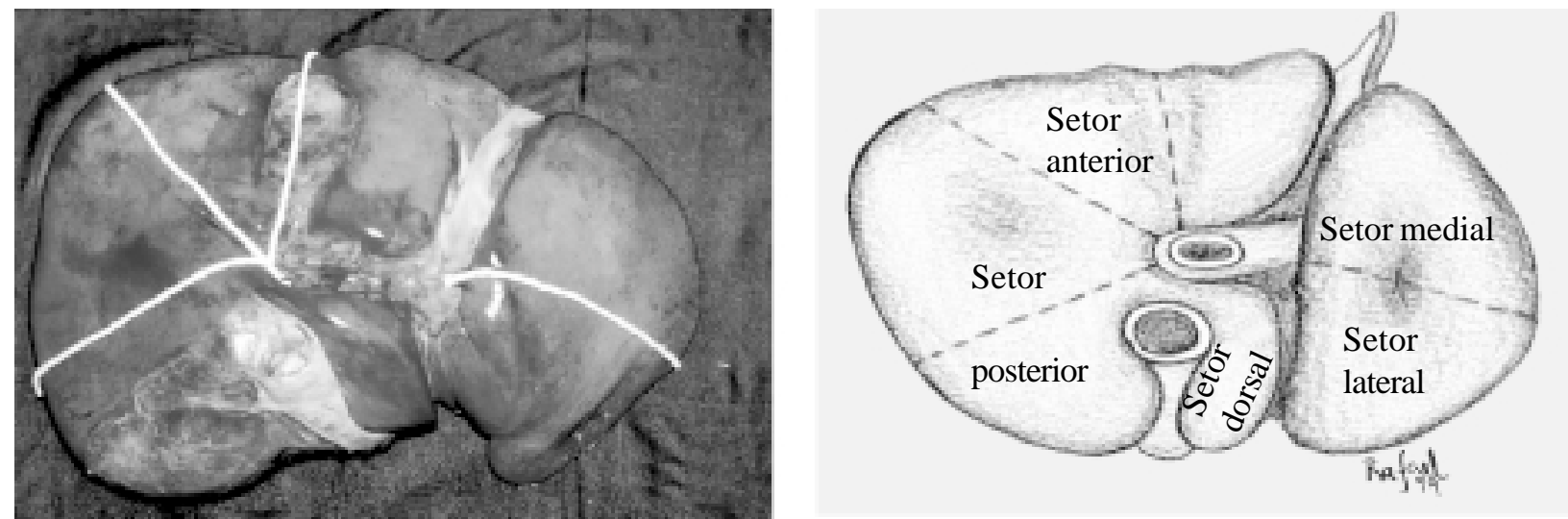

FIGURA 12 - Setores portais. Face inferior.

Os setores hepáticos, assim definidos pelas cisuras portais, são, por sua vez, subdivididos em segmentos.

À exceção do setor lateral esquerdo, os demais setores são divididos, cada um deles, em dois segmentos.

Uma linha transversa, na parte média dos setores anterior e posterior direitos, que se projeta ao nível do hilo hepático, divide estes setores em segmentos superiores e inferiores, cada um deles albergando no seu interior uma tríade portal.

A fissura umbilical, por sua vez, divide o setor medial esquerdo em dois segmentos, um lateral e outro medial. A porção anterior do segmento lateral corresponde ao lobo quadrado da anatomia morfológica.
O setor lateral esquerdo, por sua vez, é o único que não sofre divisão, e corresponde, na sua totalidade, a um segmento da divisão proposta por Couinaud ${ }^{4}$.

O setor dorsal ou lobo caudado, ou, ainda, lobo de Spiegel, é um setor independente dos demais, recebendo fluxo portal de ramos diretos dos troncos portais direito e esquerdo, e sua drenagem venosa se faz diretamente por ramos que drenam para a veia cava retro-hepática. Â semelhança do setor lateral esquerdo, este setor corresponde a um segmento na classificação de Couinaud ${ }^{4}$.

Os segmentos hepáticos, segundo os critérios propostos por Couinaud ${ }^{4}$ recebem numeração de 1 a 8 , no sentido horário, empregando-se algarismos romanos (Figuras 13 e 14).
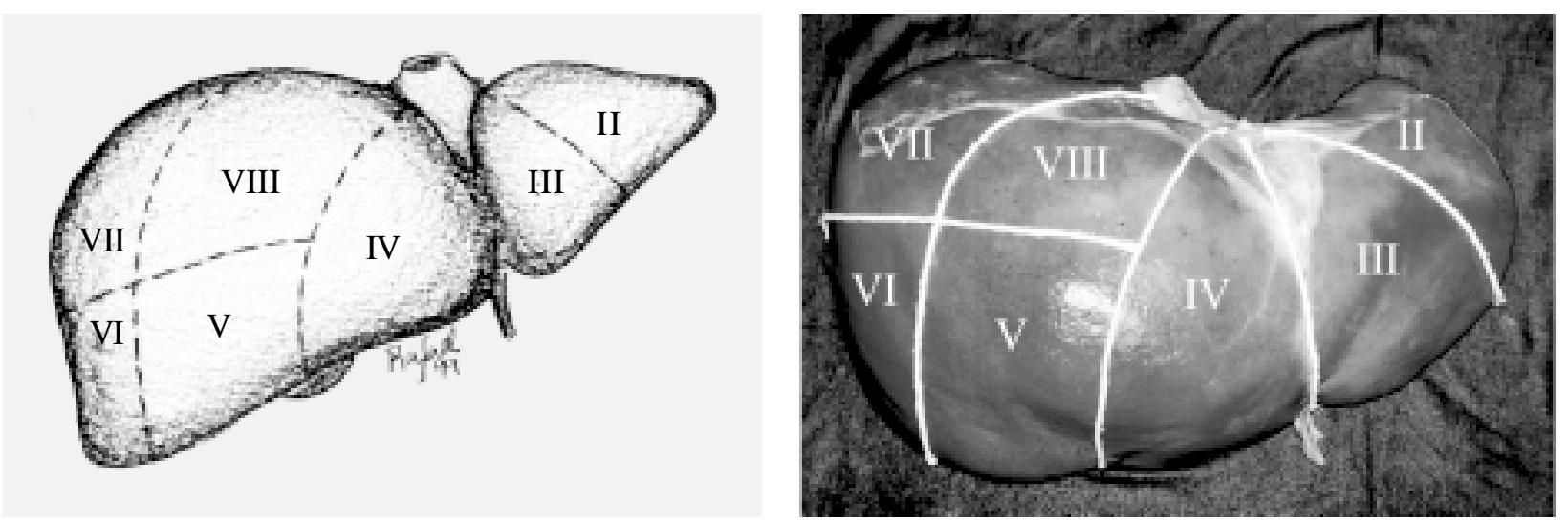

FIGURA 13 - Segmentos hepáticos. Face ântero-superior. 

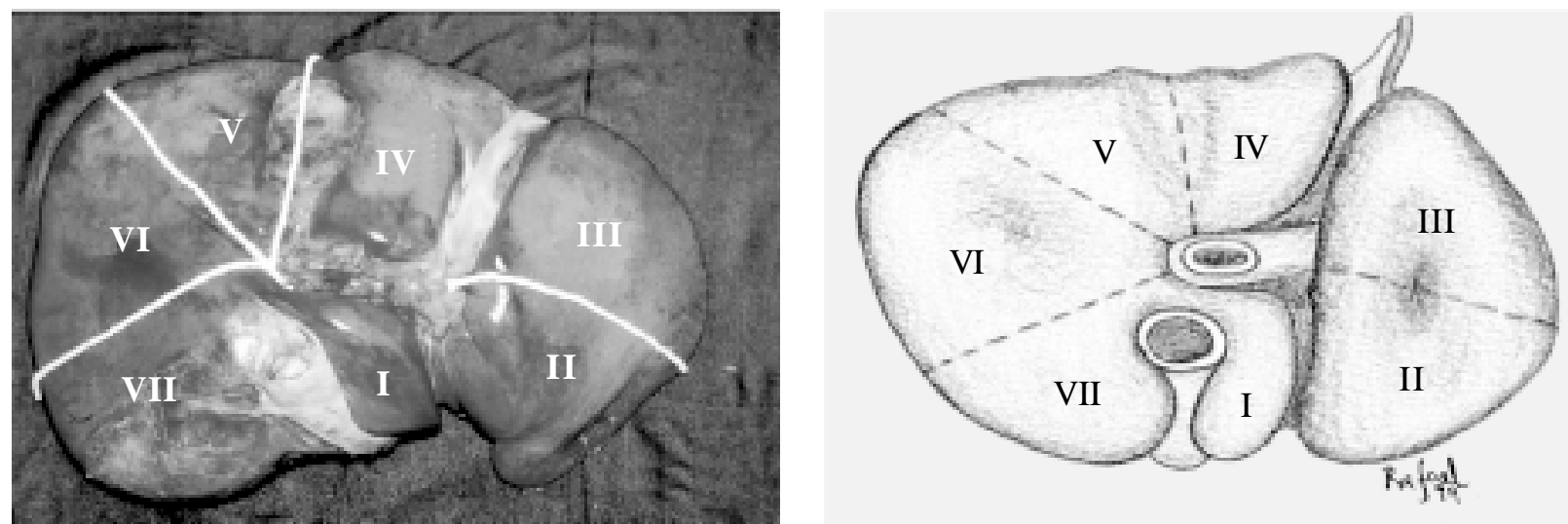

FIGURA 14 - Segmentos hepáticos. Face inferior.

Segmento I = setor dorsal ou segmento dorsal ou lobo de Spiegel

Segmento II = setor lateral

Segmento III = porção medial do setor medial

Segmento IV = porção lateral do setor medial

Segmento $\mathrm{V}=$ porção inferior do setor anterior

Segmento VI = porção inferior do setor posterior posterior

Segmento VII = porção superior do setor anterior

Segmento VIII = porção superior do setor

Recentes estudos anatômicos têm subdividido o segmento I ou setor dorsal em duas porções, uma, esquerda que mantém a designação de segmento I e outra, direita, que passa a receber a denominação de segmento IX'

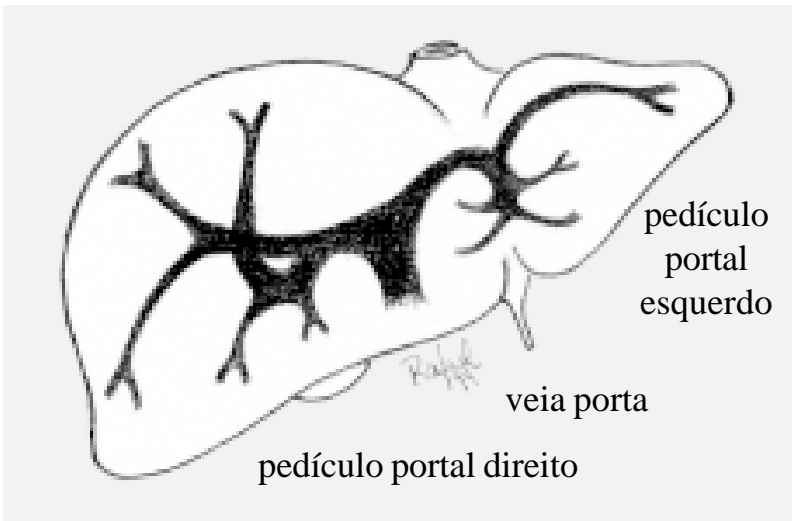

FIGURA 15 - Distribuição do tronco e ramos da veia porta.

Como unidade individualizada, cada segmento pode ser removido, isolada ou associadamente a outros,
A fim de evitar confusões na anatomia e conseqüentemente na definição das ressecções hepáticas, é importante lembrar que na terminologia proposta por Goldsmith e Woodburne ${ }^{3}$ e também por Tung ${ }^{7}$, os setores de Couinaud ${ }^{4}$ são denominados segmentos e os segmentos, denominados subsegmentos.

Consequentemente, as setorectomias e segmentectomias de Couinaud ${ }^{4}$, são por eles designadas segmentectomias e subsegmentectomias, respectivamente.

Neste trabalho, seguiremos a segmentação proposta por Couinaud ${ }^{4}$, e a remoção de cada uma destas porções será designada segmentectomia e enumerada de I a VIII, como na anatomia.

Cada segmento hepático constitui uma unidade funcional do fígado, recebendo uma tríade portal individualizada, e sendo drenado por ramo de uma das veias hepáticas (Figuras 15 e 16).

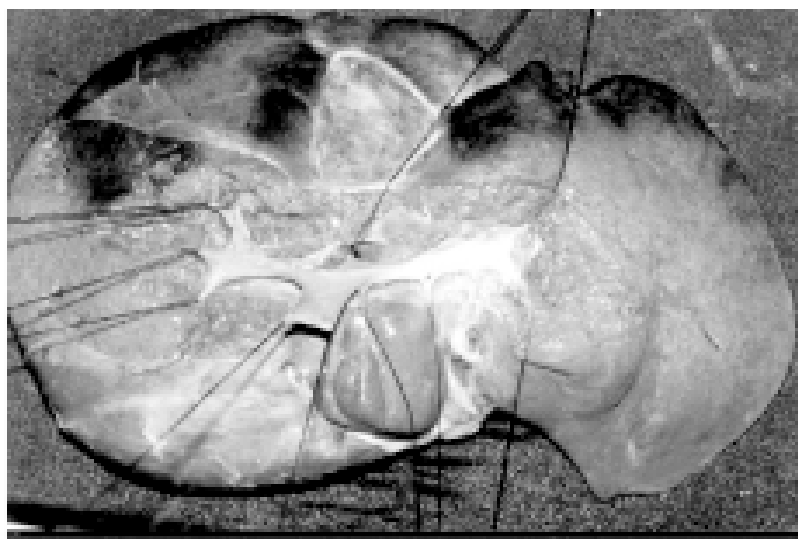

sem prejuízo da irrigação, drenagem e até das funções dos demais (Figura 17). 


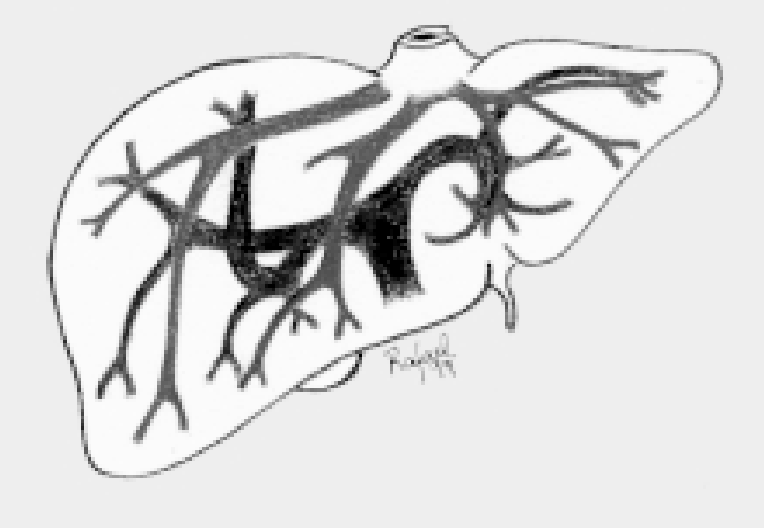

FIGURA 16 - Distribuição intra-hepática dos ramos vasculares e das veias porta e hepáticas.

As ressecções de um ou no máximo três segmentos, adjacentes ou isolados, constituem na definição de Tung7, as "ressecções hepáticas menores" anatômicas, típicas ou regradas, e constituem a essência deste trabalho.

\section{Referências}

1. McIndoe AH, Counseller VS. The bilaterality of the liver. Arch Surg 1927;15:589-612.

2. Hjortsjö $\mathrm{CH}$. The topography of the intrahepatic duct system. Acta Anat 1951;11:599-615.

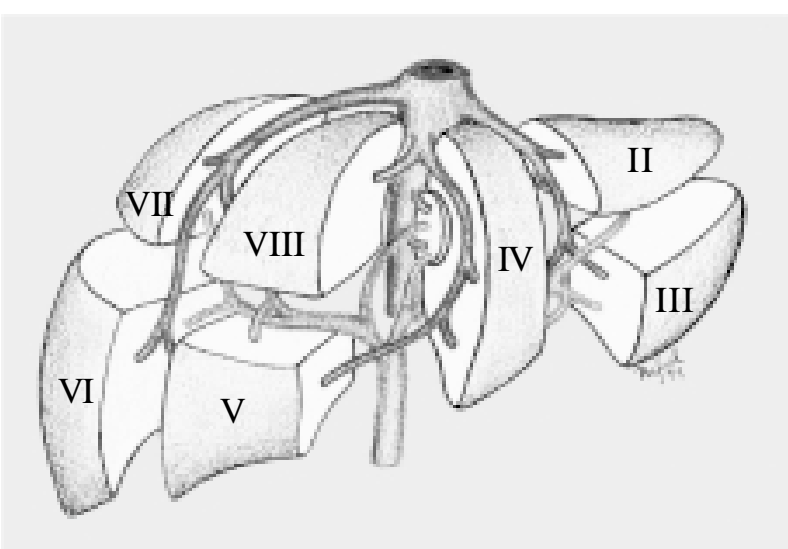

FIGURA 17 - Relação dos pedículos e dos segmentos hepáticos.

3. Goldsmith NA, Woodburne RT. The surgical anatomy pertaining to liver resection. Surg Gynecol Obstet 1957;195:310-8.

4. Couinaud C. Le foie: études anatomiques et chirurgicales. Paris: Masson; 1957

5. Bismuth H, Castaing D, De la Torre AG. Chirurgie d'exérèse des métastases hépatiques des cancers colo-rectaux. Chirurgie 1986;112:45-9.

6. Couinaud C. New look on resection of segment VII of the human liver. Arg Bras Cir Dig 1994;9:71-85.

7. Tung TT. Les résections majeures et mineures du foie. Paris: Masson; 1979

Triviño T, Abib SCV. Surgical anatomy of the liver. Acta Cir Bras [serial online] 2003 Sept-Oct;18(5). Available from URL: http://www.scielo.br/acb.

ABSTRACT - Purpose: The aim of this article is to sudy the functional anatomy of the liver and its segmentation, based on vascular (venous) structures in the parenquima. Methods: Liver dissection in recent cadavers, identifying the portal pedicles and hepatic veins, which define the liver segments or its functional units. Results: Anatomic caracterization of the eight liver segments, its afferent and efferent vascular structures, in order to guide anatomical resections that preserve the function and irrigation of the remaining segments. Conclusion: The knowledge of functional anatomy of the liver, based on its segmentation, is the basis of the modern hepatic surgery.

KEY WORDS - Functional anatomy. Hepatic segmentation. Liver.

Correspondência:

Dr. Tarcisio Triviño

Av. Rouxinol, 900/62

04516-001 São Paulo - SP

Tel: (11)5055-3484

trivino@uol.com.br

Conflito de interesse: nenhum Fonte de financiamento: nenhuma

Data do recebimento: $28 / 06 / 2003$

Data da revisão: 10/07/2003

Data da aprovação: 21/07/2003 